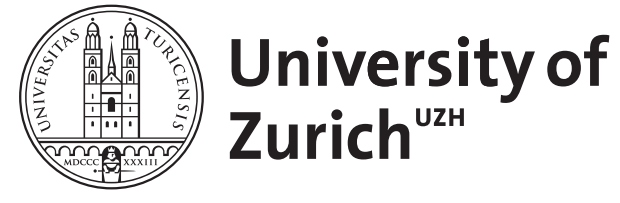

\title{
Discomfort and costs in epistaxis treatment
}

\author{
Nikolaou, G ; Holzmann, D ; Soyka, Michael B
}

\begin{abstract}
Epistaxis is a very common ENT event. Apart from the effectiveness of the different treatment options, the discomfort and the financial burden are of great importance. It has been the aim of this study to obtain data regarding the discomfort/pain of the epistaxis treatments and to calculate the financial burden. During the period between April 2010 and July 2011 epistaxis patients at our hospital had the opportunity to rate the discomfort/pain they experienced during their treatment on a 0-10 VAS scale. The costs of epistaxis treatments were calculated in an extended cohort. 84 VAS scores in 61 patients were acquired and the costs of treatment were calculated in 96 patients. The lowest VAS scores were found in chemical and electric coagulation with 1.5 and 2.0, respectively, followed by surgery (3.0), Rapid Rhino(®) packing (6.0) and balloon pack (7.5). The costs of treatments depended on whether the treatment was in an out- or inpatient setting. Surgery was not significantly more expensive than packing methods in the inpatient setting. Anterior epistaxis could be managed by local coagulation with an acceptable impact/cost ratio. At our institution, surgery was the most cost effective and the least troublesome procedure in posterior bleedings, preceded by Rapid Rhino(®) packing if required.
\end{abstract}

DOI: https://doi.org/10.1007/s00405-012-2339-2

Posted at the Zurich Open Repository and Archive, University of Zurich

ZORA URL: https://doi.org/10.5167/uzh-78139

Journal Article

Published Version

Originally published at:

Nikolaou, G; Holzmann, D; Soyka, Michael B (2013). Discomfort and costs in epistaxis treatment. European Archives of Oto-Rhino-Laryngology, 270(8):2239-2244.

DOI: https://doi.org/10.1007/s00405-012-2339-2 


\title{
Discomfort and costs in epistaxis treatment
}

\author{
Georgios Nikolaou • David Holzmann • \\ Michael B. Soyka
}

Received: 3 July 2012/ Accepted: 17 December 2012/Published online: 5 January 2013

(C) Springer-Verlag Berlin Heidelberg 2013

\begin{abstract}
Epistaxis is a very common ENT event. Apart from the effectiveness of the different treatment options, the discomfort and the financial burden are of great importance. It has been the aim of this study to obtain data regarding the discomfort/pain of the epistaxis treatments and to calculate the financial burden. During the period between April 2010 and July 2011 epistaxis patients at our hospital had the opportunity to rate the discomfort/pain they experienced during their treatment on a $0-10$ VAS scale. The costs of epistaxis treatments were calculated in an extended cohort. 84 VAS scores in 61 patients were acquired and the costs of treatment were calculated in 96 patients. The lowest VAS scores were found in chemical and electric coagulation with 1.5 and 2.0, respectively, followed by surgery (3.0), Rapid Rhino ${ }^{\circledR}$ packing (6.0) and balloon pack (7.5). The costs of treatments depended on whether the treatment was in an out- or inpatient setting. Surgery was not significantly more expensive than packing methods in the inpatient setting. Anterior epistaxis could be managed by local coagulation with an acceptable impact/ cost ratio. At our institution, surgery was the most cost effective and the least troublesome procedure in posterior bleedings, preceded by Rapid Rhino ${ }^{\circledR}$ packing if required.
\end{abstract}

Keywords Epistaxis - Treatment · Discomfort . Pain $\cdot$ Costs $\cdot$ Surgery

G. Nikolaou ( $\square)$ · D. Holzmann · M. B. Soyka Department of Otorhinolaryngology, Head and Neck Surgery, University Hospital, Frauenklinikstrasse 24, 8091 Zürich, Switzerland

e-mail: georgios.nikolaou@usz.ch

\section{Introduction}

Epistaxis is a common event within the general population. It has been stated that up to $60 \%$ of the general population experiences at least once an episode of epistaxis and $6 \%$ of people with epistaxis require medical attention [1]. Due to its mainly self-limiting course, it is often considered a minor medical event and yet it represents the most frequent rhinologic emergency [2]. Epistaxis is commonly divided into anterior and posterior bleedings depending on whether the source is visible upon anterior rhinoscopy. Several treatment options are available, depending upon the location of the bleeding source. Although the anatomy of each nose, the cause of epistaxis and the coexisting medical conditions can widely vary, there have been efforts to establish therapeutic algorithms and attempts to standardise epistaxis treatment at many institutions. There is only scarce literature available that compares the pain that different treatment options cause [3-7].

As with many other acute and chronic diseases, pain plays a major role in profiling the compliance of a patient and thus affecting improvement of the condition of the patient. Patients who are satisfied with their improvement are more compliant with treatment recommendations [8].

Administrative and overall health care costs show a consistent increase over the years [9]; and as competition in the health care sector increases, the pressure on hospitals to reduce overall costs also increases [10]. Cost effectiveness in health care could also protect from phenomena like medical bankruptcy [11].

Knowing the pain and cost of epistaxis treatment and matching them with existing data about the efficacy of each treatment, we may be able to suggest our department that an epistaxis treatment model is effective, less painful and economical [12]. 


\section{Materials and methods}

Study

The study was conducted prospectively in accordance with the latest version of the Helsinki declarations. The protocol was approved by the local ethics committee and review board.

\section{Treatment}

Our hospital is a tertiary referral centre dealing with almost 600 epistaxis' patients annually. Each patient referred to our hospital with epistaxis was first examined in our ambulatory care unit. The treatment each patient received was in accordance to the treatment algorithm previously published [12]. This involves an initial treatment of less invasive options which can be expanded depending on efficacy. If the conservative treatments fail, patients are kept in hospital and surgical therapy is considered.

Prior to packing and cautery, we anaesthetize the nose using oxybuprocaine spray or cotton pledgets soaked in oxybuprocaine. All patients received the same local anaesthesia. For the treatment of anterior epistaxis electric or chemical cautery was the treatment of choice and seldom was a pack used. For posterior epistaxis, an inflatable Rapid Rhino ${ }^{\circledR}$ packing was used $(7.5 \mathrm{~cm}$ anterior-posterior, ENT Arthrocare Europe, Stockholm, Sweden). In cases where bleeding cannot be controlled by the above mentioned method, a Foley catheter is used and is inserted through the nose until the epipharynx is reached, where it is then inflated and the nasal cavity is packed with fatty-gauze. Patients with Rapid Rhino ${ }^{\circledR}$ packing were treated either in an in- or outpatient setting. Patients who were hemodynamically unstable or had no good bleeding control with packing or received Foley catheter packing were treated in an inpatient setting. If this measure is not able to control bleeding a transnasal sphenopalatine artery closure is performed with diathermy and/or external ligation of the ethmoidal arteries under general anaesthesia [13]. At the end of each treatment, patients were asked to provide information about the levels of discomfort they experienced, with regards to the procedure that they had undergone.

\section{Patients}

Patients who were treated for epistaxis, either as outpatients or inpatients, were included in the period between April 2010 and July 2011. Bleedings secondary to trauma or caused by hereditary haemorrhagic telangiectasia (M. Osler) were excluded.

The following information was collected for each patient: age, sex, type of bleeding (i.e. anterior/posterior), type of treatment and visual analogue scale score for the evaluation of pain (VAS score). Costs were calculated for each treatment or treatment combination.

\section{Discomfort/pain}

A VAS questionnaire was handed out to all patients, who were treated for epistaxis.

84 VAS scores in 61 patients were acquired. The patients were asked to record the discomfort experienced on a 10-cm 11-point VAS scale (0: no pain, 10: most severe pain imaginable) for each treatment they received. If the patient underwent more than one treatment, each event was analysed separately. The evaluation form was handed out to the outpatients after the end of each treatment. With regards to patients who received packing, the levels of discomfort during insertion, remaining or removal of the device were not distinguished.

\section{Costs}

Costs of treatment were calculated in 96 patients. For all patients that provided VAS data, costs were calculated in accordance to the cost calculating system used in our institution. Because of the small number of treatments in some subgroups, we additionally calculated the treatment costs of a number of patients from our previous study to increase case load for the different treatments [12].

For the outpatients, the costs of epistaxis treatment were calculated based on the actual time, type of treatment and material used. This includes physical examination, the use of an electrocautery device and potential further visits i.e. for the removal of packing. Costs of all packing material were also included. Generally, patients without packing did not undergo any further visits. Patients with packing had a follow-up visit for the removal of the packing and endoscopy of the nose.

For inpatients, the costs were calculated on the basis of a fixed rate plus a daily charge, depending on the length of the stay. In this formula all medical accomplishments and services are included. No additional costs were charged for separate medical investigations/treatments or surgery. Follow-up costs for inpatients were included, as for the outpatients, in the overall costs.

\section{Statistics}

Two primary endpoints were defined as the total costs of each treatment and pain/discomfort score experienced by the patient. Median values and $95 \%$ confidence intervals are provided for both the cost and VAS analyses. Comparison between treatment groups was accomplished by Mann-Whitney testing. Comparison between two VAS ratings for the same patient were analysed by the Wilcoxon 
matched-pairs signed rank test. The significance level alpha was set to 0.05 .

\section{Results}

The costs of treatment were calculated for the cases of 96 patients and the results can be found in Table 1 .

A significant difference resulted in the costs between electric cautery, chemical coagulation and Rapid Rhino ${ }^{\circledR}$ on the one hand and all other treatment combinations on the other hand as it can be viewed in Fig. 1. Bipolar coagulation along with chemical coagulation and Rapid Rhino ${ }^{\circledR}$ packing showed the lowest costs whereas there is a increase in costs for the latter depending on the use in an out- or inpatient setting.

All therapy options used in the inpatient setting showed much higher costs with a smaller spread. The costs for these therapies depended on the duration of hospitalisation.

84 VAS scores from 61 patients were acquired. The male to female ratio was 5:3 with a median age of 72 years (range 18-89), while 45 patients had anterior whereas 16 were found to have posterior epistaxis. The provided VAS scores are shown in Table 2. There was no significant difference in the VAS scores $(p=0.7)$ between the treatment options that were used for anteriorly located bleeding sources (Fig. 2).

Amongst treatment options for posterior located bleeding sources, there was a wide spread of VAS scores, with a statistically significant difference between Rapid Rhino ${ }^{\circledR}$ packing and surgery $(p=0.03)$ and between the balloon packing and surgery $(p=0.02)$.

From those patients who required both packing and surgery, a separate rating was obtained following both treatments resulting in a time-dependent paired analysis shown in Fig. 3. A significantly lower discomfort value is presented in the direct comparison $(p=0.02)$.

\section{Discussion}

The ideal treatment for epistaxis should have three characteristics: low-discomfort, cost effectiveness and low

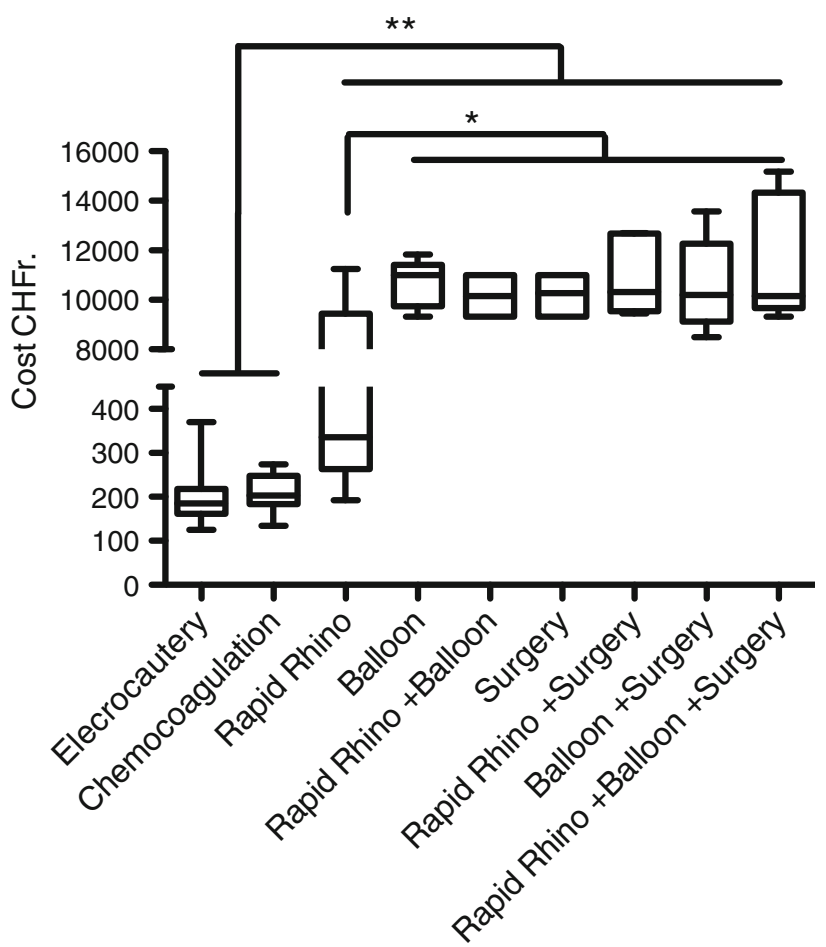

Fig. 1 Costs in Swiss Francs (CHF) for each treatment and combination. Significant differences are indicated $(* p<0.05$ and ** $p<0.01)$

Table 2 Median VAS scores are provided along with upper and lower confidence intervals and number of treatments

\begin{tabular}{lll}
\hline Treatment & Total no $(n)$ & Median VAS score $(95 \% \mathrm{CI})$ \\
\hline Chemical coagulation & 14 & $1.5(1.45,3.98)$ \\
Bipolar coagulation & 40 & $2.0(2.26,3.78)$ \\
Rapid Rhino ${ }^{\circledR}$ packing & 15 & $6.0(4.18,7.16)$ \\
Surgery & 11 & $3.0(1.8,4.93)$ \\
Balloon packing & 4 & $7.5(3.71,11.29)$ \\
\hline
\end{tabular}

level of recurrences. The results indicate the differences in discomfort and pain between the various treatment groups. Surgery not only is less troublesome to the patient, but also does not increase the costs of treatment.
Table 1 Median costs in Swiss Francs are provided along with upper and lower confidence intervals and number of treatments

\begin{tabular}{lcl}
\hline Treatment & Total no $(n=96)$ & Costs median $(95 \%$ CI $)$ \\
\hline Bipolar coagulation & 36 & $185.6(173.2,209.6)$ \\
Chemical coagulation & 6 & $203.0(159.8,257.6)$ \\
Rapid Rhino ${ }^{\circledR}$ packing & 17 & $335.6(834.2,5,653)$ \\
Rapid Rhino $^{\circledR}$ packing + surgery & 10 & $10,309(9,872,11,823)$ \\
Rapid Rhino $^{\circledR}$ packing + balloon packing & 5 & $10,160(9,123,11,197)$ \\
Rapid Rhino ${ }^{\circledR}$ packing + balloon packing + surgery & 5 & $10,160(8,463,14,806)$ \\
Balloon packing & 5 & $10,995(9,479,11,843)$ \\
Balloon packing + surgery & 6 & $10,192(8,680,12,517)$ \\
Surgery & 6 & $10,269(9,407,10,986)$ \\
\hline
\end{tabular}




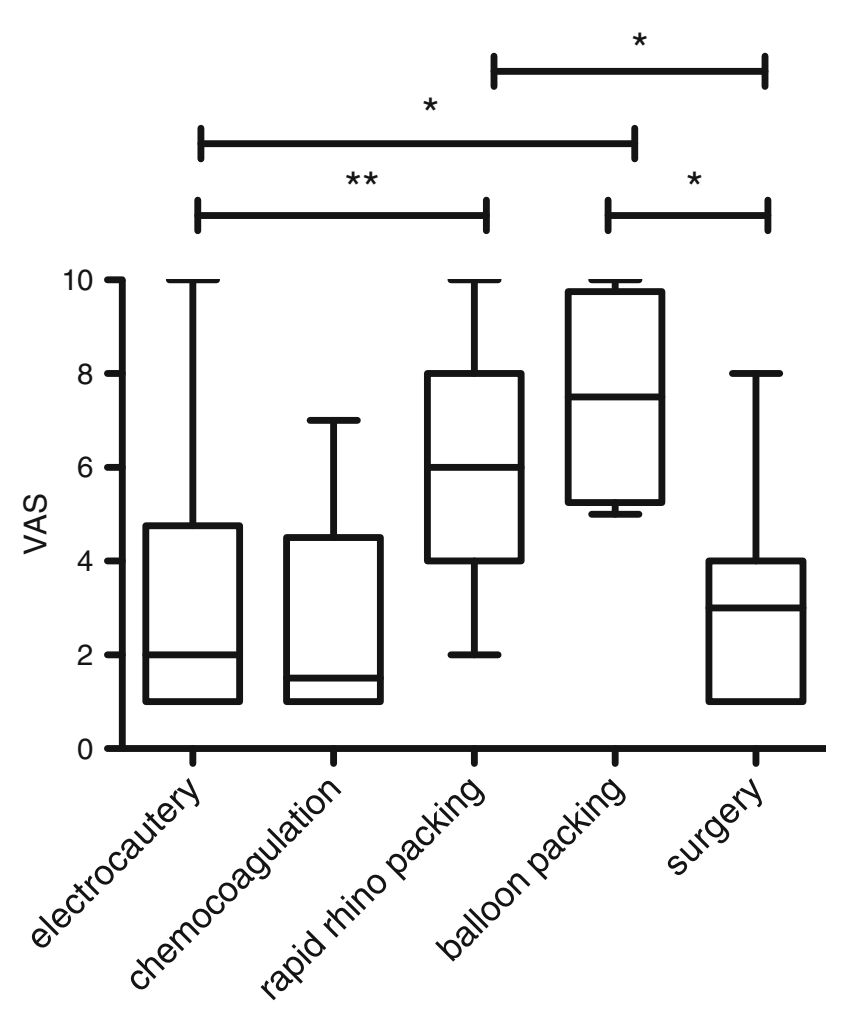

Fig. 2 Visual analogue scale scores for different treatments. Significant differences are indicated $(* p<0.05, * * p<0.01)$

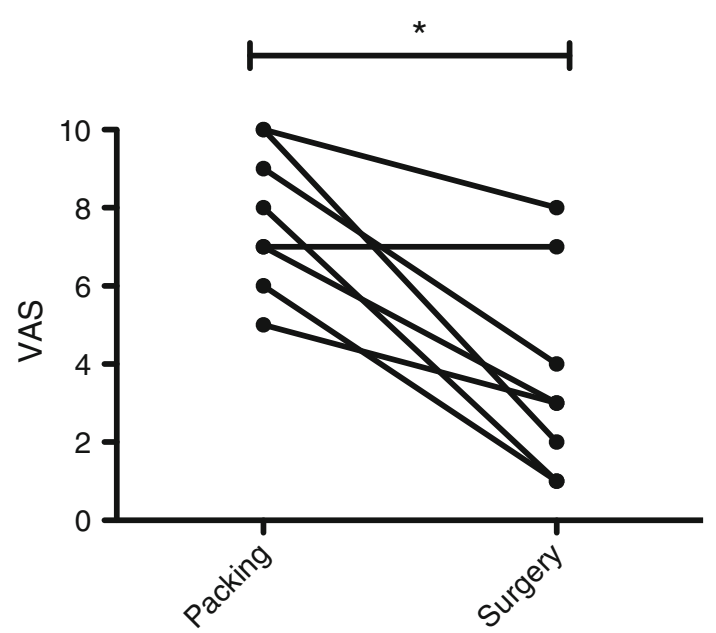

Fig. 3 Patients who received both treatments (packing and surgery) and who rated both treatments showed significantly less discomfort by the surgical treatment. Results from Wilcoxon matched-pairs rank test $n=8$

\section{Limitations of the study}

While using a prospective approach, we believe that the relatively low caseload poses potential limitations in the study of treatment costs. To overcome this source of bias and to increase the validity of our cost analysis, we additionally calculated the costs of a number of treatments from our previously published retrospective study.

Anterior epistaxis

According to the results of this study, it can be stated that anterior epistaxis can be treated with either electric or chemical coagulation causing no significant differences in discomfort and with similar economic burden.

It is known from previous investigations that chemical coagulation is more prone to failure [12]. From this point of view, we conclude that it would be better to treat an anterior epistaxis with electrocautery, if possible, as all treatment failures lead to increased costs and repetitive discomfort.

\section{Posterior epistaxis}

Amongst the treatment options available for posterior epistaxis, there are significant differences in the VAS scores. The lowest median VAS score was caused by surgery, followed by Rapid Rhino ${ }^{\circledR}$ and balloon packing. It has been shown that the majority of patients with nasal packing can be safely managed in an outpatient setting [14]. In a previous study, discomfort upon insertion or removal of Rapid Rhino ${ }^{\circledR}$ or Merocel was assessed and a significant difference, with Rapid Rhino ${ }^{\circledR}$ causing less discomfort on insertion or removal, has been shown [5]. There are also a number of studies showing that the discomfort caused by Rapid Rhino ${ }^{\circledR}$ is less than for other nasal packing methods not used in our study [4-7]. There is no doubt that a skilled surgeon is required to perform sphenopalatine artery closure. And yet, in many hospitals around the world efforts are made to treat patients with posterior bleeding primarily with surgery instead of conservative treatment $[15,16]$. Complications seen by the use of packing further support our belief that surgical treatment is better in managing posterior epistaxis.

Regarding the economic burden that treatment options for posterior epistaxis cause, there is no significant difference between Rapid Rhino ${ }^{\circledR}$ surgery and the balloon packing. A wide range of costs within the Rapid Rhino ${ }^{\circledR}$ treated group and a large difference between anterior and posterior treatments have been recorded. This fact is caused by the different requirements to hospitalise a patient. While Rapid Rhino ${ }^{\circledR}$ can be used safely in an outpatient setting as long as the bleeding is well controlled and the patient's general condition allows the discharge, other treatments might require an in-hospital stay. As shown in our previous study, surgery has significantly fewer failures than packing [12]. In a review of transnasal sphenopalatine artery occlusions, either through ligation or diathermy, the overall success rate to control bleeding ranged from 92 to $100 \%$ with a mean of $98 \%$. The literature suggests higher 
success rates if the sphenopalatine artery ligation is performed simultaneously with anterior ethmoidal artery ligation [16].

The major parameter that plays a role in cost calculation is the duration of the hospitalisation and this has been shown to be shorter for surgery than for nasal packing [15].

For posterior epistaxis, the costs, when comparing surgery with the other treatment options are not different. According to our cost analysis surgical treatment is not as expensive as assumed; this is in concordance with other studies [12, 15, 17].

Former studies stated that nasal packing has significantly lower hospital charges than surgery or intraarterial embolisation and patients who did not come to operation had fewer complications, a shorter hospital stay, and lower costs [18, 19]. One limitation of our study has been the use of the local cost calculating system. Although other health care systems could come to other calculations, our results are fully in concordance with current literature that showed lower costs and better success of surgery when used as first line treatment in posterior epistaxis [15]. Two studies that were performed in 2004 and 2006 have shown that there are highly significant differences between surgery and packing not only regarding the efficacy but also the duration of hospital stay and the cost reduction [20, 21].

Intraarterial embolization has not been included in our treatment options due to the limited number of interventions in Zurich during the study period. A recent study about arterial embolization in the management of posterior epistaxis has shown ability to control bleeding in acute setting of $88 \%$ comparable with older reports but arterial embolization requires a well-organised setting and skilled interventional radiologists. The risks of these procedures

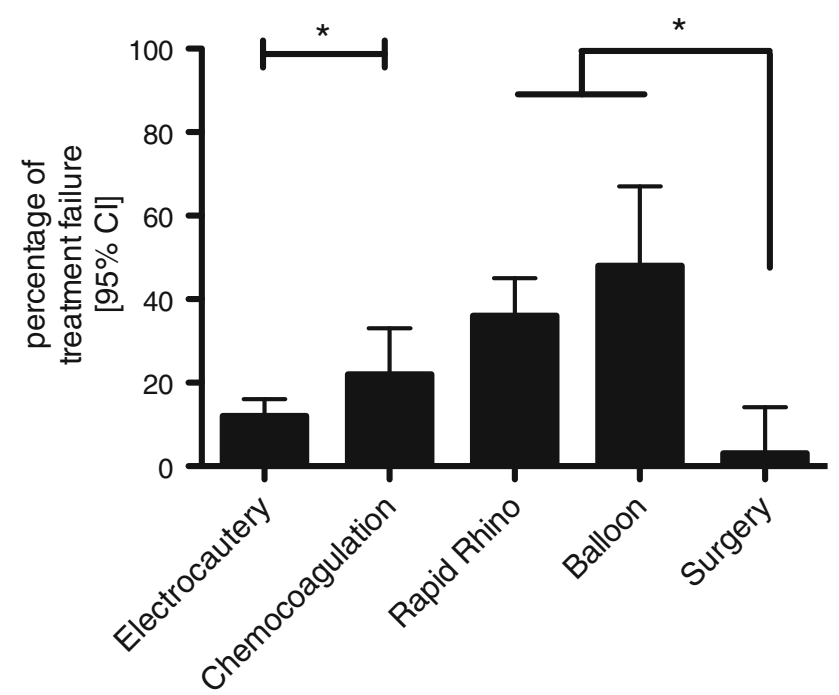

Fig. 4 Treatment failures from a previously published large cohort study [12]. Asterisk indicating significant differences like cerebrovascular accidents although small should be taken into account [22]. Miller and Stevens [23] described that there was no economic advantage for angiography compared with transnasal endoscopic sphenopalatine artery ligation.

Combining our results while looking at the treatment failures of the different treatment options of an antecedent study (Fig. 4), it can be easily concluded that balloon packing is expensive, prone to failure and causes the most discomfort to patients.

\section{Conclusion}

According to the VAS scores obtained and costs calculated within the context of recurrences, the best treatment option for posterior epistaxis appears to be a temporary packing with a Rapid Rhino ${ }^{\circledR}$ nasal pack and consecutive surgery.

With these option two therapies with a relatively low VAS-discomfort score are used, the costs are similar to other combinations used in the inpatient setting and recurrences are infrequent. Local cautery seems to be the therapy of choice in anterior bleedings. Our findings further support the idea of training young otolaryngologists to become skilled endonasal surgeons to control nosebleeds surgically.

Conflict of interest All authors state that there are no conflicts of interest to disclose. There are no financial disclosures.

\section{References}

1. Viehweg TL, Roberson JB, Hudson JW (2006) Epistaxis: diagnosis and treatment. J Oral Maxillofac Surg 64(3):511-518. doi: S0278-2391(05)01815-X

2. Small M, Murray JA, Maran AG (1982) A study of patients with epistaxis requiring admission to hospital. Health Bull (Edinb) 40(1):20-29

3. Toner JG, Walby AP (1990) Comparison of electro and chemical cautery in the treatment of anterior epistaxis. J Laryngol Otol 104(8):617-618

4. Badran K, Malik TH, Belloso A, Timms MS (2005) Randomized controlled trial comparing Merocel and Rapid Rhino packing in the management of anterior epistaxis. Clin Otolaryngol 30(4): 333-337. doi:COA1019

5. Moumoulidis I, Draper MR, Patel H, Jani P, Price T (2006) A prospective randomised controlled trial comparing Merocel and Rapid Rhino nasal tampons in the treatment of epistaxis. Eur Arch Otorhinolaryngol 263(8):719-722. doi:10.1007/s00405006-0047-5

6. Chheda N, Katz AE, Gynizio L, Singer AJ (2009) The pain of nasal tampon removal after nasal surgery: a randomized control trial. Otolaryngol Head Neck Surg 140(2):215-217. doi:S01945998(08)01407-1

7. Singer AJ, Blanda M, Cronin K, LoGiudice-Khwaja M, Gulla J, Bradshaw J, Katz A (2005) Comparison of nasal tampons for the treatment of epistaxis in the emergency department: a randomized controlled trial. Ann Emerg Med 45(2):134-139. doi: S0196064404014957 
8. Hirsh AT, Atchison JW, Berger JJ, Waxenberg LB, LafayetteLucey A, Bulcourf BB, Robinson ME (2005) Patient satisfaction with treatment for chronic pain: predictors and relationship to compliance. Clin J Pain 21(4):302-310. doi:00002508-200507 000-00004

9. Woolhandler S, Himmelstein DU (1997) Costs of care and administration at for-profit and other hospitals in the United States. N Engl J Med 336(11):769-774. doi:10.1056/NEJM1997 03133361106

10. Altman SH, Shactman D (1997) Should we worry about hospitals' high administrative costs? N Engl J Med 336(11):798-799. doi:10.1056/NEJM199703133361111

11. Himmelstein DU, Thorne D, Warren E, Woolhandler S (2009) Medical bankruptcy in the United States, 2007: results of a national study. Am J Med 122(8):741-746. doi:S0002-9343(09) 00404-5

12. Soyka MB, Nikolaou G, Rufibach K, Holzmann D (2011) On the effectiveness of treatment options in epistaxis: an analysis of 678 interventions. Rhinology 49(4):474-478. doi:10.4193/Rhin

13. Soyka MB, Rufibach K, Huber A, Holzmann D (2010) Is severe epistaxis associated with acetylsalicylic acid intake? Laryngoscope 120(1):200-207. doi:10.1002/lary.20695

14. Van Wyk FC, Massey S, Worley G, Brady S (2007) Do all epistaxis patients with a nasal pack need admission? A retrospective study of 116 patients managed in accident and emergency according to a peer reviewed protocol. J Laryngol Otol 121(3): 222-227. doi:10.1017/S0022215106003148

15. Klotz DA, Winkle MR, Richmon J, Hengerer AS (2002) Surgical management of posterior epistaxis: a changing paradigm. Laryngoscope 112(9):1577-1582. doi:10.1097/00005537-200209 000-00008
16. Kumar S, Shetty A, Rockey J, Nilssen E (2003) Contemporary surgical treatment of epistaxis. What is the evidence for sphenopalatine artery ligation? Clin Otolaryngol Allied Sci 28(4): 360-363. doi: 724

17. Wang L, Vogel DH (1981) Posterior epistaxis: comparison of treatment. Otolaryngol Head Neck Surg 89(6):1001-1006

18. Goddard JC, Reiter ER (2005) Inpatient management of epistaxis: outcomes and cost. Otolaryngol Head Neck Surg 132(5): 707-712. doi:S0194599805001518

19. Schaitkin B, Strauss M, Houck JR (1987) Epistaxis: medical versus surgical therapy: a comparison of efficacy, complications, and economic considerations. Laryngoscope 97(12):1392-1396. doi:10.1288/00005537-198712000-00003

20. Moshaver A, Harris JR, Liu R, Diamond C, Seikaly H (2004) Early operative intervention versus conventional treatment in epistaxis: randomized prospective trial. J Otolaryngol 33(3):185188

21. Rejas Ugena E, Trinidad Ruiz G, Alvarez Dominguez J, Carrasco Claver F, Pino Rivero V, Blasco Huelva A (2006) Utility of the surgical treatment for severe epistaxis by endoscopic approach of sphenopalatine and ethmoidal arteries. Acta Otorrinolaringol Esp 57(5):228-234

22. Christensen NP, Smith DS, Barnwell SL, Wax MK (2005) Arterial embolization in the management of posterior epistaxis. Otolaryngol Head Neck Surg 133(5):748-753. doi:S0194-5998(05) 01752-3

23. Miller TR, Stevens ES, Orlandi RR (2005) Economic analysis of the treatment of posterior epistaxis. Am J Rhinol 19(1):79-82 